\title{
Nutritional Challenges and Health Consequences of Junk Foods
}

\author{
Harmanjot Kaur ${ }^{1 *}$ and Roopjot Kochar ${ }^{2}$ \\ ${ }^{1}$ Nutritionist, SGS Ayurvedic Diet and Nutrition, India \\ ${ }^{2}$ Director, SGS Ayurvedic Diet and Nutrition, India
}

Submission: March 03, 2019; Published: May 07, 2019

*Corresponding author: Harmanjot Kaur, Nutritionist, SGS Ayurvedic Diet and Nutrition, Khanna, Punjab, India

\begin{abstract}
Junk food refers to fast food, which are easy to make and easy to consume. They are low in nutritional value and have only lying fat in it causing ill effect on the health of consumer. Junk food contains high level of refined sugar, white flour, Trans fat, polyunsaturated fat salt and numerous food additives such as monosodium glutamate (MSG) and tartrazine, and lacking in protein, vitamin and fiber. It should be avoided, because of lack of energy, high cholesterol and poor concentration. It causes a lot of harmful effect on the body like obesity, diabetes, heart disease and various types of skin cancers.

Keywords: Fast food; Consumption; Nutritional challenges; Health consequences; Balanced diet; Eating habits; High value foods; Overweight; High blood pressure; Blood glucose; Cholesterol; Communicable diseases; Processed foods

Abbreviations: Fast food; Consumption; Nutritional challenges; Health consequences; Balanced diet; Eating habits; High value foods; Overweight; High blood pressure; Blood glucose; Cholesterol; Communicable diseases; Processed foods
\end{abstract}

\section{Introduction}

'Junk food' was coined by Michael Jacobson, in 1972 in the public interest who wanted to raise public attention about the issue of foods with a high caloric value and a low nutritional value. The report of fast food market in India 2015-2020 drawn attention that Indian fast food market is expected to grow at a compound annual growth rate (CAGR) of $18 \%$ by 2020 due to changing consumer behavior and demography; it is expected to be worth US $\$ 27.57$ billion by 2020 . Balanced diet has been replaced by junk or fast foods not only by young generation but also people from all age group demand fast food in their everyday eating habits, due to rapid increase in disposable income with changing attitude towards food choices act as a driving force for processed food which resulted in changing consumption pattern away from traditional food to processed and high value foods. These high calorie foods are steeply damaging human health and lead to metabolic changes and conditions such as becoming overweight, high blood pressure and raised blood glucose and cholesterol which are among the leading causes of death due non communicable diseases in India [1].

Another study points out that consumption of junk food create problems to people health as there is no nutrition and obesity only accounts for 300,000 deaths in the U.S alone. The research found there is a direct relationship between the numbers of fast food restaurant and occurrence of obesity [2]. It Points out that fried and processed foods contain high amounts of trans fats, saturated fats in addition to oxcycholestrol which may prove dangerous to heart health as reported by scientists from china in the National meeting of the American chemical society.

\section{Health Consequences of Junk Food Consumption}

Frequent fast food consumption is a major health concern because most fast food rich in saturated fats, trans fats, simple carbohydrates and sodium all are nutrients which are associated with hypertension, cardiovascular diseases and type 2 diabetes. Calorie content consumed by the children of out of home meals is 55 per cent higher than of in-home meals. According to the research, the consumption of fast food on a regular basis leads to excess energy intake leading to an increased risk of overweight and obesity [2]. A study on prevalence of fast food intake among adolescents of Srinagar city in Northern India revealed that fast food consumption was universal in the all age group of 14-18 years. 
It was only in the age group of 19 years that 4.16 per cent respondents were not eating fast foods. In the age group of 15 and 18 years, around 50 per cent of respondents skipped lunch. More than 60 per cent of subjects in the age group of 16 and 18 years spend their entire pocket money on fast foods whereas in the age group of 17 and 19 years only 50 per cent and 41.66 per cent respondents pocket money was affected by eating fast food, respectively. Frequency of consumption of fast food was higher in all the age groups. During morning none of the children were consuming fast foods as they usually spent the time period at their homes.

On the one hand sex and economic status were found to be chief variable in fast food consumption as girls are leading in former and adolescent students reading/ studying in private schools are up in the latter [3]. Fast food consumption was to the extent of 97.3 per cent among high school boys in Mangalore city in Southern India [4]. Experts therefore attribute the current childhood obesity epidemic to fast foods. This increase in childhood obesity has led to increase in lifethreatening conditions particularly non communicable diseases in developing countries [5]. Dental cavities another common ailment in school children can result due to dense sugar content in fast foods. Food additives used in these food stuffs are found to be carcinogenic and can be allergic causing asthma and rashes which are also seen frequently among children. Added to this in developing countries there are problems like poor hygiene during preparation, storage and handling of fast foods leading to contamination by microorganisms [6].

Obesity is multi factorial disorder of energy balance in which chronic calorie intake is greater than energy output. It is characterized by an excessive body mass index (BMI), which is weight $(\mathrm{kg})$ divided by the square of height $(\mathrm{m} 2)$. A subject with a BMI of 20-25 is considered as having a healthy body weight, one with a BMI as 25-30 overweight and one with a BMI> 30 as obese. The management of obesity is maintaining proper diet and increased physical activity. At present approximately 33 per cent adult in USA and 20 per cent middle aged population in Europe are obese.

Diabetes mellitus is a chronic metabolic disorder characterized by hyperglycemia, glycosuria, hyperlipemia, negative nitrogen balance and sometimes ketonemia. Diabetes mellitus is of two types, Type I (insulin dependent) and Type II (insulin independent). Over 90 per cent cases are Type II diabetics due to junk food consumption. Junk food consists of salt abundance which raises the blood pressure which can causes hypertension, coronary thrombosis and other cardiovascular diseases. Dental cavities formed due to the excessive consumption of junk food because food accumulated on teeth spaces and plaque formation occurs which finally results in dental cavities.

It causes kidney impairment like polyuria, renal failure and hyperuricaemia. Mental disorders i.e. drowsiness, laziness, dyslexia, attention deficient hyper activity disorder [ADHD], loss of balance and lack of concentration occur due to excessive eating of junk food [7]. Vegetarian diet or non-vegetarian diet did not have any effect on prevalence of underweight, overweight and obesity, but junk food consumption leads to more prevalence of obesity and overweight than underweight indicates that caloric intake is associated with increase in BMI. Junk foods are mainly made up by using a lot of saturated fats which are unhealthy after digestion and release a lot of toxins into the body. Moreover, it lacks vitamins and minerals which are necessary to have good health and immunity to fight diseases.

The practice of high consumption of junk foods like magi noodles, burgers, sandwiches, hot dogs, patties, pastries, popcorn, potato chips, carbonated drinks, biscuits, muffins, toast, chocolates etc. have become common feature of adolescent's diet [8]. Ill effects of regular intake of junk foods are mainly lack of energy, poor concentration and obesity leading to inferiority complex, depression, heart diseases, high cholesterol, stunted growth, premature ageing, and tooth decay [9].

Changes in lifestyle and loss of the family tradition of eating together trigger the popularity of fast foods among young people. The shift from healthy, homemade food to more convenient, longer lasting fast foods combined with a sedentary lifestyle has resulted in global fattening and related health complications. Regular eating of fast food can increase the risk of weight gain and obesity because of having a high energy density with the presence of high levels of fat and sugar in the meal, and a correspondingly low level of fiber and protein [10].

A study conducted among urban private medical students in Bangladesh showed that a quarter of respondents were overweight which is higher than the national average [11]. Modern diet has following four key impacts on health as:

a) Under-nutrition causes nutrition deficiency, and over nutrition leads to obesity, hypertension, hyperlipidemia, diabetes and cancer. Nutritional requirements may vary among different individuals with different heredity and family backgrounds, different dietary habits and living in different countries.

b) Contribution of foods and nutrition to the immune system is apparent, which is also a hot topic of research on functional foods. However, increasing number of studies indicate that immune defense is the first priority of nutrition. Hypo-immunity is only observed in infants, children, and elderly and in individuals with diseases and serious nutrition defects. Thus, when nutrition is abundant, even commonly redundant, excessive immunity can cause inflammation, autoimmune diseases, and metabolic syndromes.

c) Another problem is that precise effect of foods on organs or tissues within the body is unclear. Some studies have shown that food mainly interacts with the GI mucous 
membrane system. Communication between organs and tissues is established through the circulatory and signaling systems of the GI tract and inner system. The metabolic and cellular communication networks provide feasible ways and can be evaluated by obtaining only a few millimeters cube of peripheral blood.

Finally, the last one is related to Public health being a social and political concept aimed at the improving health, prolonging life and improving the quality of life among whole populations through health promotion, disease prevention and other forms of health intervention [12]. People who drink minimal amounts of alcohol are at a risk of causing non-alcoholic fatty liver disease, characterized by the accumulation of fat in the liver [13]. Risk factors for developing nonalcoholic fatty liver disease are high cholesterol and high triglycerides, which develop from a high intake of saturated fat, trans fat, sugar and cholesterol, all of which are found in junk foods [14,15]. Malnutrition is also a risk factor for non-alcoholic fatty liver disease. Most junk foods contain a lot of calories and fat but lacks important vitamins and minerals which are very essential for the body [16]. People those with non-alcoholic fatty liver disease may experience fatigue, weight loss and pain in the upper right quadrant of the abdomen [17]. For some people, non-alcoholic fatty liver disease does not cause any serious complications. For others, the disease can lead to inflammation of the liver which led to liver scarring and reduced liver function [18]. Another study was conducted to find out "Fruit, Vegetables and Fast Food Consumption among University Students" which indicated that "two thirds of the university students from Timisoara are not eating fruits and vegetables daily", while guidelines recommend consuming 5 portions of fruit and vegetables each day to prevent cardiovascular disease.

Besides, 26 per cent of students from Timisoara university center were often consuming unhealthy fast foods. Three main factors responsible for choosing fast food found in students from Timisoara University center are lack of time, lack of money and school program [19]. A study shows that the multiple factors are related to inappropriate dietary practices like fast food consumption, cold drinks, low fruit and vegetable intake, irregular sleeping habits, less physical activity, unhealthy daily routine and pursuance of different forms of risk behaviors. The study also showed an association of life style with several other variables and suggests need for urgent attention to deal with the emerging health risks and promoting factors of health through relevant policy-oriented reformulation, coordinated efforts among individuals and initiating culturally appropriate lifestyle interventions among adolescents [20,21].

\section{Conclusion}

Consumption of fast food among people seems to have an adverse effect on dietary quality in ways that could increase risk for obesity, heart diseases etc. Consuming junk foods or fast foods on a regular basis leads to many health hazards. But bringing about changes in eating habits is not so easy. Fast food is a kind of addictive in spite of knowing that it is unhealthy, most of the people get hooked on to it and continue consuming it in an uncontrolled way. Fast foods are good in taste, but lack all the necessary nutrients and therefore, unhealthy in the long run if consumed on a regular basis leading to various disorders which may be fatal at times. To start with, a simple change that one could make is to successively reduce the frequency of eating fast food or junk food and eat more frequently homecooked food including plenty of fresh foods and vegetables. Fast food is deficient in dietary fiber and essential micro-nutrients like vitamins and minerals which are required for body to stay healthy. Making nutritional information available at fast food restaurants helps the consumers to order low calorie items which would be more beneficial and healthful. Eating frequent fast food meals causes an individual to gain more weight and face an increased risk of developing disorders like Obesity, Type 2 Diabetes, non-alcoholic fatty liver disease and cardiac diseases etc.

\section{References}

1. Keshari P, Mishra CP (2016) Growing menace of fast food consumption in India: time to act. International Journal of Community Medicine and Public Health 3: 1355-1362.

2. Ashakiran, Deepthi R (2012) Fast food and their impacts on health. Journal of Krishna Institute of Medical Sciences University1(2): 7-15.

3. Vaida N (2013) Prevalence of fast food intake among urban adolescent students. IJES 2(1): 353-359.

4. Joseph N, Nelliyanil M, Rai S, Raghavendra BYP, Kotian SM, et al. (2015) Fast food consumption pattern and its association with overweight among high school boys in Mangalore City of southern India. J Clin Diagn Res 9(5): 13-17.

5. Jaisheeba AA, Sornaraj R, Gayathri K (2012) Influence of westernized culture and changed dietary habits on the BMI status of the school children of Tirunelveli. International Journal of Pharm Tech Research 4(1): 1065-1077.

6. Kaushik JS, Narang M, Parakh A (2011) Fast food consumption in Children. Indian Pediatrics 48(2): 97-101.

7. Bhaskar R (2012) Junk food: Impact on health. Journal of Drug Delivery \& Therapeutics 2(3): 67-73.

8. Ibrahim U, Ismail UF, Mohammed M (2014) Nutritional knowledge, attitude and junk food consumption habits among Abubakar Tatari Ali Polytechnic, Bauchi students. International Journal of Scientific \& Engineering Research 5(12): 26-28.

9. Chhibber C (2010) Children Hooked to Junk Food: Schools Fail to Curb the Menance. The Tribune, Ludhiana. Is Junk food healthy? p. 1-2.

10. Jaworowska A, Blackham T, Davies IG, Stevenson L (2013) Nutritional challenges and health implications of takeaway and fast food. Nutrition Reviews 71(5): 310-318.

11. Rasul FB, Shawon MSR, Nazneen S, Hossain FB, Malik SS (2013) Do the dietary and lifestyle practices make the private medical students overweight: A cross-sectional study in Bangladesh? Journal of Biology, Agriculture and Healthcare 3(2): 130-139.

12. Shridhar G, Rajendra N, Murigendra H, Shridevi P, Prasad M (2015) Modern Diet and its Impact on Human Health. Journal of Nutrition and Food Sciences 5(6): 1-3. 


\section{Current Research in Diabetes \& Obesity Journal}

13. Khosravi S, Alavian SM, Zare A, Daryani NE, Fereshtehnejad SM (2011) Non-alcoholic fatty liver disease and correlation of serum alanin aminotransferase level with histopathologic findings. Hepatitis Monthly 11(6): 452-458.

14. Castellanos MI, Seijas OR, González D, Ronquillo M, Del Rosario Abreu M (2011) Immune Alterations in Liver Cirrhosis: Its Relationship with Etiology, Child Pugh Stage and Malnutrition. Journal of Nutritional Disorders and Therapy 1: 101.

15. Dhibi M, Brahmi F, Mnari A, Houas Z, Chargui I (2011) The intake of high fat diet with different trans fatty acid levels differentially induces oxidative stress and non-alcoholic fatty liver disease (NAFLD) in rats. Nutr Metab (Lond) 8(1): 65.

16. Barchetta I, Angelico F, Del Ben M, Baroni MG, Pozzilli P (2011) Strong association between non alcoholic fatty liver disease (NAFLD) and low $25(\mathrm{OH})$ vitamin D levels in an adult population with normal serum liver enzymes. BMC Medicine 9: 85.
17. Rahimi AR, Daryani NE, Ghofrani H, Taher M, Pashaei MR (2011) The prevalence of celiac disease among patients with non-alcoholic fatty liver disease in Iran. Turk J Gastroenterol 22(3): 300-304.

18. El-Koofy NM, El-Karaksy HM, Mandour IM, Anwar GM, El-Raziky MS (2011) Genetic polymorphisms in non-alcoholic fatty liver disease in obese Egyptian children. Saudi J Gastroenterol 17(4): 265-270.

19. Avram C, Oravitan M (2013) Fruit, vegetables and fast food consumption among university students. Timisoara Physical Education and Rehabilitation Journal 5(10): 54-60.

20. Vaishali P (2015) Health Hazards and Knowledge about Junk Foods-A Review. International Journal of Nursing Research 1(2): 146-157.

21. Muthukumar E (2014) Changing behavior of eating habits relates to junk food among college students. International Journal of Business and Administration Research Review 2(7): 151-155.

Your next submission with Juniper Publishers
will reach you the below assets
- Quality Editorial service
- Swift Peer Review
- Reprints availability
- E-prints Service
- Manuscript Podcast for convenient understanding
- Global attainment for your research
- Manuscript accessibility in different formats
( Pdf, E-pub, Full Text, Audio)
- Unceasing customer service
Track the below URL for one-step submission
https://juniperpublishers.com/online-submission.php

